\title{
REVIEW
}

\section{Spina bifida: A multidisciplinary perspective on a many-faceted condition}

G Fieggen, ${ }^{1}$ BSc (Med), MB ChB, MSc, MD, FCS (SA); K Fieggen, ${ }^{2}$ MB ChB, FCPaed (SA), Cert Med Genet (SA);

C Stewart, ${ }^{3} \mathrm{MB}$ ChB, MMed, MA, FCOG (SA); L Padayachy, ${ }^{1}$ MB ChB, MMed, FCNeurosurg (SA);

J Lazarus, ${ }^{4}$ MB ChB, MMed Urology, MA, FCUrol (SA); K Donald, ${ }^{5}$ MB ChB, MPhil, FCPaed (SA), MRCPCH (UK), Cert Paed Neurology (SA);

S Dix-Peek, ${ }^{6} \mathrm{MB}$ ChB, MMed, FCOrth (SA); Z Toefy, ${ }^{7} \mathrm{RN}$; A Figaji, ${ }^{1} \mathrm{MB}$ ChB, MMed, PhD, FCNeurosurg (SA)

${ }^{1}$ Division of Neurosurgery, University of Cape Town and Spina Bifida Clinic, Red Cross War Memorial Children's Hospital, Cape Town, South Africa

${ }^{2}$ Division of Medical Genetics, University of Cape Town and Spina Bifida Clinic, Red Cross War Memorial Children's Hospital, Cape Town, South Africa

${ }^{3}$ Department of Obstetrics and Gynaecology, University of Cape Town and Fetal Medicine Unit, Groote Schuur Hospital, Cape Town, South Africa

${ }^{4}$ Division of Urology, University of Cape Town and Spina Bifida Clinic, Red Cross War Memorial Children's Hospital, Cape Town, South Africa

${ }^{5}$ Division of Developmental Paediatrics, University of Cape Town and Spina Bifida Clinic, Red Cross War Memorial Children's Hospital,

Cape Town, South Africa

${ }^{6}$ Division of Orthopaedic Surgery, University of Cape Town and Spina Bifida Clinic, Red Cross War Memorial Children's Hospital,

Cape Town, South Africa

${ }^{7}$ Spina Bifida Clinic, Red Cross War Memorial Children's Hospital, Cape Town, South Africa

Corresponding author: G Fieggen (graham.fieggen@uct.ac.za)

Open spina bifida or myelomeningocele (SBM) is the most common birth defect involving the central nervous system, second only in incidence to congenital cardiac disease. Outcomes in this disorder were poor until the mid-20th century, when modern neurosurgical techniques (closing the lesion and treating hydrocephalus) and treatment for the neuropathic bladder addressed the major causes of mortality, although SBM may still be poorly treated in the developing world. Initial management - or mismanagement - has a profound impact on survival and long-term quality of life.

S Afr Med J 2014;104(3):213-217. DOI:10.7196/SAMJ.8079

Myelomeningocele is the most complex congenital abnormality compatible with long-term survival. - David McLone

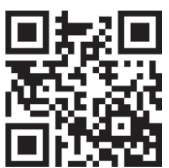

Open spina bifida or myelomeningocele (SBM) is the most common birth defect involving the central nervous system, second only in incidence to congenital cardiac disease. Although recognised since antiquity, with anthropological relics depicting affected individuals and suggestive descriptions in the writings of Hippocrates and Galen, the first definitive description was by the Dutch clinician Peter van Forest in 1610. His compatriot, Nicholas Tulp, famous for Rembrandt's 'The anatomy lesson of Dr Tulp', introduced the term spina bifida 31 years later, along with the first clear illustration of the condition. ${ }^{[1]}$

Despite various attempts at treatment, outcome remained very poor until the mid-20th century. The development of modern neurosurgery (closure of the lesion and treatment of hydrocephalus) and the advent of treatment for the neuropathic bladder addressed the major causes of mortality. More recently, advances in antenatal diagnosis and perhaps, most important of all, successful prevention strategies through the use of preconception folic acid, led to a fall in the number of new cases.

SBM is, however, still common throughout much of the developing world, and many patients remain poorly treated. There are few conditions where initial management (or mismanagement) has such a profound impact on survival and long-term quality of life. Appreciation of the value of various specialties working together led to the establishment of multidisciplinary spina bifida clinics. One such 
clinic was established at Red Cross War Memorial Children's Hospital in 1967 (J C de Villiers - personal communication). This review, and the accompanying articles written by members of this clinic, aims to highlight the key challenges in management, demonstrate the value of multidisciplinary care, and emphasise the need to offer better treatment in South Africa (SA) in order that these children and adults can achieve their true potential.

\section{Terminology}

The term spina bifida is used to refer to a range of different conditions. The simplest form is incomplete closure of the posterior elements of one of the lower lumbar or sacral vertebrae. This is very common (around $10 \%$ of the population) and incidentally noted on X-ray, but seldom of any clinical relevance. Spina bifida occulta or closed spina bifida refers to a range of rare but characteristic congenital abnormalities involving the lower spinal cord, such as a lipoma, myelocystocele or split cord; usually there is an overlying cutaneous abnormality (such as a subcutaneous lipoma, naevus or hairy patch) and pathophysiologically the spinal cord is tethered and vulnerable. Spina bifida aperta or open spina bifida is almost always a myelomeningocele, where the spinal cord and meninges are exposed on the dorsal surface of the infant at

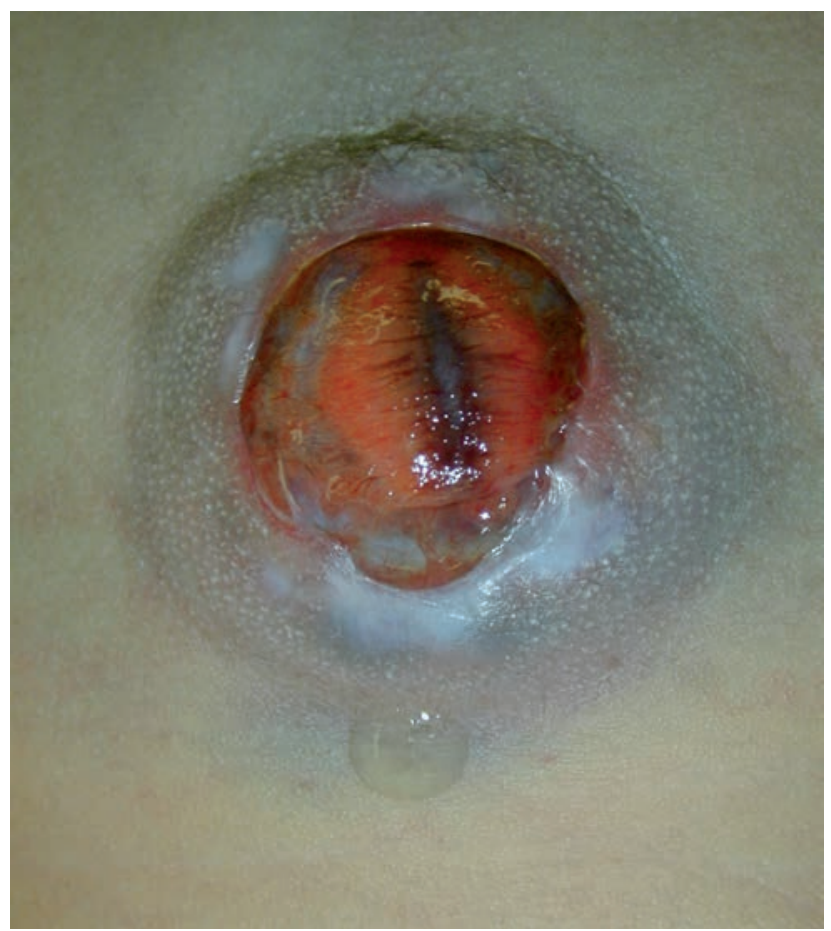

Fig. 1. Clinical photograph showing a typical myelomeningocele. The open spinal cord is readily appreciated, with the midline fold continuous rostrally with the central canal of the spinal cord. Leaking CSF can also be seen. birth (Fig. 1). This is invariably accompanied by a range of other central nervous system abnormalities (Fig. 2).

Spina bifida is part of a spectrum of conditions referred to by the term dysraphism, which encompasses a range of conditions (Table 1) that result from an embryological error, usually abnormal closure of the neural tube.

\section{Embryology and prevention}

Virtually the entire central nervous system develops from ectoderm, with the neuro-ectoderm thickening into a neural plate which then folds over to close in the midline through the process of primary neurulation. ${ }^{[2]}$ This process occurs extremely early in embryonic life (completed by day 28) and errors lead to neural tube defects (NTDs). Presenting as either anencephaly at the rostral (brain) end or myelomeningocele at the caudal (spinal) end, the incidence of NTDs ranges from 0.77 to 6.1/1 000 live births in SA, with higher incidences reported in rural areas. ${ }^{[3]}$ The lower sacral segments form through the more complex process of caudal regression or secondary neurulation and errors result in various forms of spina bifida occulta, such as caudal lipoma.

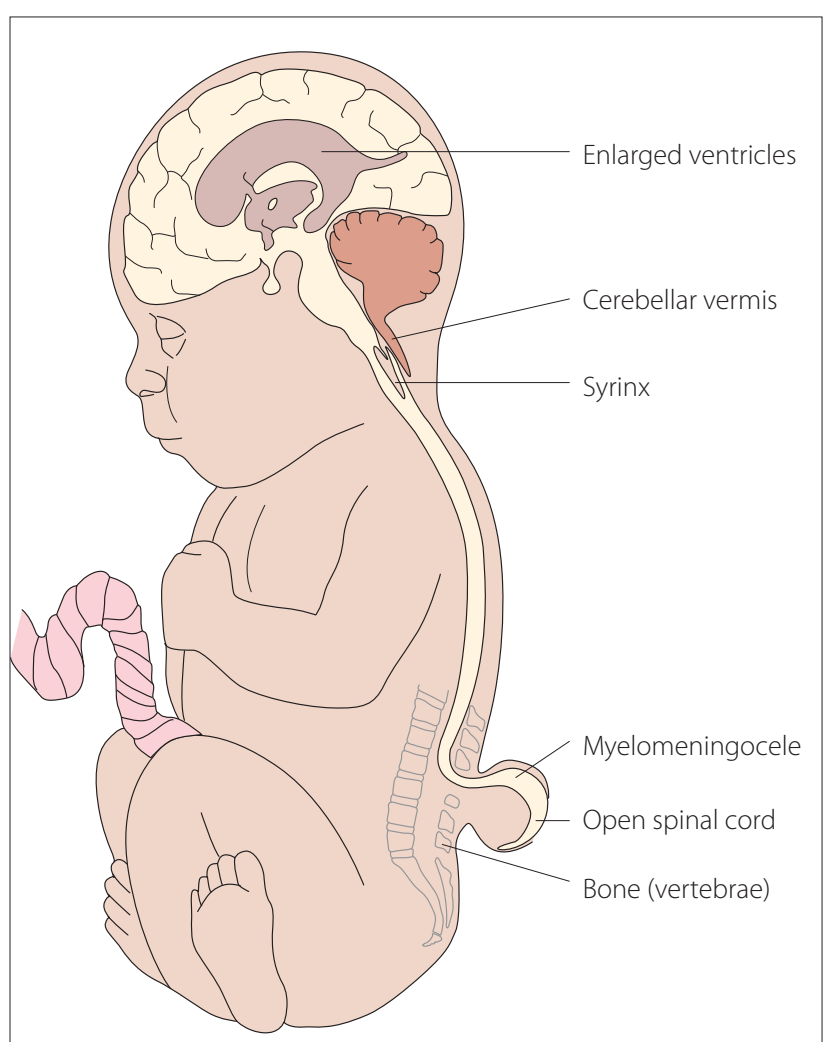

Fig. 2. Diagram showing sagittal impression of the myelomeningocele and Chiari II malformation. 
Table 1. Classification of dysraphism

\begin{tabular}{cl}
\hline Cranial & \\
Open & Anencephaly (and occasional encephaloceles) \\
Closed & Encephalocele; cranial dermal sinus \\
Spinal & \\
Open & Spina bifida aperta: myelomeningocele/meningomyelocele \\
Closed & Spina bifida occulta
\end{tabular}

One of the most effective primary prevention strategies ever described is the prevention of NTDs by administration of folic acid prior to conception, a strategy that is supported by evidence from a number of prospective randomised trials in various countries. ${ }^{[4]}$ One of the public health strategies this has led to is food fortification, which was successfully implemented in SA. ${ }^{[5]}$ The mechanism by which folate supplementation reduces the incidence of NTDs is unknown - genetic factors clearly play an important role and the aetiology can truly be described as multifactorial.

\section{Antenatal diagnosis}

Although maternal serum alpha-fetoprotein remains a useful screening investigation, the focus has shifted to prenatal ultrasound screening, which should detect more than $90 \%$ of cases. ${ }^{[6]}$ Performing an anatomical scan at 18 - 23 weeks requires appropriate training as a level 3 scanner, since the consequences of missing the diagnosis can be very costly, as evidenced by the magnitude of 'wrongful birth' medicolegal claims. An antenatal diagnosis of SBM should be followed by nondirective counselling, allowing the family to choose between terminating or continuing the pregnancy. Although a prospective trial showed some benefit following intrauterine closure of SBM, ${ }^{[7]}$ there is still some scepticism about the true benefit of this intervention which is not yet available in SA. Anyone wishing to consider this option is encouraged to contact a paediatric neurosurgeon for advice at the earliest possible opportunity. At this stage, the greatest priority in our country is to optimise primary prevention and ensure early prenatal diagnosis.

\section{Perinatal management}

For those parents who elect to continue with the pregnancy, decisions around mode of delivery should be based on obstetric criteria, although for most SBM babies born in SA the diagnosis is not made antenatally. Either way, it is obvious upon inspection of the newborn infant's back. The key imperatives are:

- initial resuscitation, taking particular care over the airway because of the potential for brainstem dysfunction

- appreciation of the fact that the lesion on the back represents the open and exposed spinal cord, which must be kept clean and sterile, ideally protected by a salinesoaked gauze dressing

- evaluation of the anatomical level of the lesion and correlating this with the neurological level (motor function in lower limbs).

The definitive treatment is surgical closure before the lesion is colonised, ideally within 24 hours but definitely within 72 hours. The goal of surgery is to close the dura mater and skin over the spinal cord to prevent central nervous system infection, but this does not reverse the congenital neurological deficit. Although a neurosurgeon should be the practitioner best trained to perform this surgery, many of these children are still managed by other surgical specialists in SA and other developing countries.

Some authors recommend administration of intravenous antibiotics if the lesion is leaking cerebrospinal fluid (CSF), as the latter may increase the risk of ventriculitis. ${ }^{[8]}$ The use of antibiotics must not engender a false sense of security, and closure should still be performed as soon as possible as this is the most effective antimicrobial strategy. In developing countries, many of these children present too late for primary closure and if the back is kept clean, the lesion may epitheliase over a period of weeks. Surgery is usually still indicated in patients who present late, as the mass tends to enlarge with time.

Postoperatively, the infant is nursed flat for 5 days to reduce pressure on the wound to avoid a CSF leak, oral feeds (ideally breastfeeding) are commenced, watching for evidence of bulbar dysfunction, and the head circumference is measured daily to monitor for hydrocephalus. The parents should be counselled by a social worker with regard to the imperative for folate prophylaxis and assisted in applying for a Care Dependency grant. A high incidence of latex allergy has been reported in SBM patients, but this was not borne out in a study in Cape Town, perhaps owing to a longstanding policy of avoiding the use of latex products in these patients from the outset. ${ }^{[9]}$

\section{Other neurosurgical issues}

Although only a minority of children born with SBM have hydrocephalus that is apparent at birth, most will go on to develop progressive hydrocephalus that requires treatment. This may entail insertion of a ventriculoperitoneal shunt, or in some centres, endoscopic surgery - third ventriculostomy, ${ }^{[10]}$ possibly with choroid plexus coagulation to reduce CSF production. ${ }^{[11]}$

With SBM, what one sees on the back is the tip of the iceberg as these patients invariably have a Chiari II malformation (often incorrectly referred to as the ArnoldChiari malformation), typical features of which are cerebellar herniation through the foramen magnum and brainstem distortion (Fig. 2). This is, however, a pancerebral malformation as the entire central nervous 
system is involved. ${ }^{[12]}$ The onset of bulbar symptoms often led to posterior decompression surgery in times past, but recognition that early brainstem dysfunction is not due to cerebellar herniation alone has led to a substantial decrease in this procedure. ${ }^{[13]}$

There are various possible causes for neurological deterioration in someone with a history of myelomeningocele, including shunt malfunction (first and foremost), Chiari II malformation, syringomyelia, progressive scoliosis and secondary tethering of the spinal cord. The last may present with neurological deterioration (such as new bladder symptoms or worsening gait) or back pain.

\section{Urological}

Bladder dysfunction is always present in SBM, resulting in a clinical picture referred to as the neurogenic or neuropathic bladder. This results in urinary incontinence as well as progressive renal damage due to recurrent urinary tract infections and dynamic factors such as high bladder storage pressures and secondary vesico-ureteric reflux. These complications can often be detected at primary care level by regular clinical assessment coupled with urinalysis and culture, serum chemistry and simple radiological studies where appropriate. More complex investigations such as invasive urodynamic studies are essential in evaluating function and planning management, but regrettably these are rarely available in SA.

The primary goals of management are to normalise bladder pressure and achieve social continence. The cornerstone of management is clean intermittent catheterisation, which in our experience can be successfully used even under adverse socio-economic circumstances. This is often supplemented by anticholinergic drugs (either oral or intravesical) and surgery when conservative management fails. ${ }^{[14]}$

\section{Developmental}

Although the focus readily falls on the obvious spinal abnormality and its direct consequences, it is important to remember that SBM is invariably accompanied by the Chiari II malformation, a pancerebral malformation, as discussed above. To this may be added the effects of hydrocephalus and its management, epilepsy, endocrine dysfunction, repeated hospitalisations and other medical complications. Despite this, the majority of SBM patients have an intelligence quotient (IQ) in the average to low average range ${ }^{[15]}$ but in some IQ is in the high range.

$\mathrm{SBM}$ is a complex neurodevelopmental disorder with a wellcharacterised cognitive pattern. ${ }^{[16]}$ The value of early awareness of the strengths and weaknesses of the individual child is obvious. While an inclusive education policy is in place in SA, few mainstream schools in the public sector are able to fully meet the needs of these children, which include learning support, physical exercise such as sport, and accessible classrooms, toilets and other facilities.

\section{Orthopaedic}

Orthopaedic surgeons have much to offer these patients, either in correcting spinal deformity or optimising mobility. Spinal deformity tends to occur only in paraplegic patients and needs surgical correction if progressive. The neurological level, which is defined as the lowest motor segment with at least MRC grade 3/5 power, is the most important factor in determining walking potential and also determines the pattern of lower limb deformities. ${ }^{[17]}$

Virtually all SBM patients require treatment of foot deformities with the goal of obtaining a plantigrade, mobile and braceable foot and avoiding trophic ulceration. ${ }^{[18]}$ Deformities, including equinus, club foot, valgus and cavovarus, can be corrected by a range of operations. Trophic ulcers are due to a stiff plantigrade foot or a neglected injury in an insensate foot; treatment often requires rotating a flap to reconstitute normal skin and fat pad as well as removing the bony prominence under the ulcer. If inadequately treated, trophic ulcers lead to significant morbidity and can result in amputation. Other complications to look for include Charcot arthropathy and fractures that can present with swelling, warmth and oedema, mimicking cellulitis or septic arthritis.

\section{Long-term quality of life}

With early closure and effective treatment of common complications such as hydrocephalus and neuropathic bladder, the majority of these patients survive into adulthood - a marked contrast to the situation 50 years ago when survival was around $10 \%$. Most modern series report survival into adulthood of well over $50 \%,{ }^{[19]}$ although there remains a troubling risk of death in adults. ${ }^{[21]}$

The focus now shifts to transition of care through adolescence and addressing the issues that impair quality of life, in addition to all the medical domains listed above. The neuropathic bladder is usually accompanied either by faecal incontinence or chronic constipation, which may necessitate daily bowel washouts. A relatively neglected area is that of sexuality and parenthood among adults with SBM. ${ }^{[21]}$ Although IQ scores suggest a good prognosis, this tends to overestimate the capacity for social integration. ${ }^{[22]}$

Various support groups and other organisations have evolved over the years, many of which work through the International Federation for Spina Bifida and Hydrocephalus (IFSBH).

\section{Closed spinal dysraphism}

Although folate prophylaxis and antenatal diagnosis have led to a fall in the number of children born with SBM, this has not affected the number of children born with closed dysraphism who have many of the same urological and orthopaedic challenges, but do not have hydrocephalus, Chiari II malformation or the cognitive issues typical of SBM. Although a magnetic resonance imaging (MRI) scan is usually required to make the diagnosis, it is usually apparent to the 
astute clinician given the almost invariable occurrence of an overlying cutaneous lesion. Missing the diagnosis may result in progressive neurological deterioration, which seldom improves following surgery.

\section{Conclusion}

SBM is a complex disorder that requires input from many different health professionals. The rewards for managing these children well are substantial as they can lead full and productive lives. Although there is no doubt about the value of a multidisciplinary clinic, the family practitioner, who co-ordinates care, is essential. With the resources available in SA, there is little doubt that these children deserve better care than they often receive.

\section{References}

1. Goodrich J. A historical review of the surgical treatment of spin bifida. In: Özek M, Cinalli G, Maixner W, eds. Spina bifida: Management and Outcome. Milan: Springer, 2008;3-17. [http://dx.doi. org/10.1007/978-88-470-0651-5_1]

. Wallingford J, Niswander L, Shaw G, Finnell R. The challenge of understanding and preventing neural tube defects. Science 2013;339:1222002. [http://dx.doi.org/10.1126/science.1222002]

3. Robertson H, Steyn N, Venter P, Christianson A. Neural tube defects and folic acid - a South African perspective. S Afr Med J 1997;87:928-931.

4. De-Regil LM, Fernández-Gaxiola AC, Dowswell T, Peña-Rosas JP. Effects and safety of periconceptional folate supplementation for preventing birth defects. Cochrane Database Syst Rev 2010;10:CD007950. [http://dx.doi.org/10.1002/14651858.CD007950.pub2.-A]

5. Sayed A, Bourne D, Pattison R, Nixon J, Henderson B. Decline in the prevalence of neural tube defects following folic acid fortification and its cost-benefit in South Africa. Birth Defects Research (Part A) 2008:82:211-216. [http://dx.doi.org/10.1002/bdra.20442]

6. Boyd P, Devigan C, Khoshnood B, et al. Screening policies in Europe for structural malformations and coyd P, Devigan C, Khoshnood B, et al. Screening policies in Europe for structural malformations and
chromosome anomalies, and their impact on detection and termination rates for neural tube defects chromosome anomalies, and their impact on detection and termination rates for neural tube defects
and Down's syndrome. Br J Obstet Gynaecol 2008:115:689-696. [http://dx.doi.org/10.1111/j.14710528.2008.01700.x]
7. Adzick N, Thom E, Spong C, et al. A randomized trial of prenatal versus postnatal repair of myelomeningocele. N Engl J Med 2011;364:993-1004. [http://dx.doi.org/10.1056/NEJMoa 1014379]

Boop F, Teo C. The perinatal management of the child born with a myelomeningocele. In: Loftus CE, ed. Neurosurgical Emergencies. Vol. II. Chicago: American Association of Neurological Surgeons, 1994:335-345.

9. Johar A, Lim D, Arif M, et al. Low prevalence of latex sensitivity in South African spina bifida . Johar A, Lim D, Arif M, et al. Low prevalence of latex sensitivity in South African spina bifida
children in Cape Town. Pediatr Allergy Immunol 2005;16:165-170. [http://dx.doi.org/10.1111/j.1399children in Cape To38.2005.00221.x]

10. Teo $\mathrm{C}$, Jones R. Management of hydrocephalus by endoscopic third ventriculostomy in patients with myelomeningocele. Pediatr Neurosurg 1995;25:57-63. [http://dx.doi.org/10.1159/000121098]

11. Warf B, Campbell J. Combined endoscopic third ventriculostomy and choroid plexus cauterization as primary treatment of hydrocephalus for infants with myelomeningocele: Long-term results of prospective intent-to-treat study in 115 East African children. J Neurosurg Pediatr 2008;2:310-316. [http://dx.doi.org/10.3171/PED.2008.2.11.310]

12. Miller E, Widjaja E, Blaser S, Dennis M, Raybaud C. The old and the new: Supratentorial MR finding in Chiari II malformation. Childs Nerv Syst 2008;24:563-575. [http://dx.doi.org/10.1007/s00381-0070528-x]

13. Gilbert J, Rorke L, James H, Jones K, Chernoff G. The pathological basis for the failure of surgery to relieve the symptomatic Arnold-Chiari malformation. Concepts Pediatr Neurosurg 1988:8:70-75.

14. Verpoorten C, Buyse G. The neurogenic bladder: Medical treatment. Pediatr Nephrol 2008:23:717-725. [http://dx.doi.org/10.1007/s00467-007-0691-z]

15. Barf H, Verhoef M, Jennekens-Schinkel A, Post M, Gooskens R, Prevo A. Cognitive status of young adults with spina bifida. Dev Med Child Neurol 2003;45:813-820. [http://dx.doi org/10.1111/j.1469-8749.2003.tb00896.x]

16. Fletcher I, Ostermaier K, Cirino P, Dennis M. Neurobehavioral outcomes in spina bifida: Processes versus outcomes. J Pediatr Rehabil Med 2008;4:311-324.

17. Hoffer M, Feiwell E, Perry R, Perry J, Bonnett C. Functional level in patients with myelomeningocele. J Bone Joint Surg Am 1973;55:137-148

8. Maynard M, Weiner L, Burke S. Neuropathic foot ulceration in patients with myelodysplasia. J Pediat Orthop 1992;2:786-788

9. Bowman R, McLone D, Grant D, Tomita T, Ito J. Spina bifida outcome: A 25-year prospective. Pediat Neurosurg 2001;34:114-120. [http://dx.doi.org/10.1159/000056005]

20. Jernigan S, Berry J, Graham D, et al. Risk factors of sudden death in young adult patients with myelomeningocele. J Neurosurg Pediatr 2012;9:149-155. [http://dx.doi.org/10.3171/2011.11. PEDS11269]

21. de Vylder A. Sexuality, sex, pregnancy, and spina bifida. In: Özek M, Cinalli G, Maixner W, eds. Spin Bifida: Management and Outcome. Milan: Springer, 2008:397-404. [http://dx.doi.org/10.1007/978-88470-0651-5_31]

22. Vinchon $M$, Dhellemmes $P$. The transition from child to adult in neurosurgery. Adv Tech Stand Neurosurg 2007;32:3-24. [http://dx.doi.org/10.1007/978-3-211-47423-5_1] 